\title{
El papel de la traducción en la reescritura de la historia reciente de Marruecos. La literatura de testimonio escrita en árabe: Hadiz al- 'atma de Fatna El Bouih
}

\author{
KATJIA TORRES \\ Universidad Pablo de Olavide \\ mtorres@upo.es
}

Recibido: 7 de diciembre de 2012

Aceptado: 14 de marzo de 2013

\section{RESUMEN}

En el presente artículo abordamos la labor de la traducción en la reescritura de la historia reciente de Marruecos escrita en árabe, así como la pertinencia del estudio contextualizado de la traducción para reducir la distancia cultural del texto original. Para ello presentamos el ejemplo del relato autobiográfico Hadiz al- 'atma de Fatna El Bouih y su utilización para la elaboración de un estudio de investigación sobre los años de Plomo en Marruecos, titulado La ruptura del silencio. Testimonios. Explicamos el proceso de elección de los textos, la metodología de traducción, y la motivación de dar prioridad al escopo de la misma.

Palabras clave: Interculturalidad, reescritura, historia, Hadiz al- 'atma, Fatna El Bouih.

The role of translation in the rewriting process of recent Moroccan history. Testimony Literature written in Arabic: Talk of darkness ${ }^{1}$ by Fatna El Bouih

\begin{abstract}
This paper focuses on the role of translation in the rewriting process of recent history written in Arabic in Morocco and in the relevance of contextualized study of the translated texts in order to become intelligible. Hadiz al- 'atma the true history of Fatna El Bouih it's presented as an example of original Arabic text to develop a research study on the Years of Lead
\end{abstract}

1 El Boulh, F., Talk of Darkness. Translated from the Arabic and introduced by Musthapa Kamal and Susan Slyomovics. The Center for Middle Eastern Studies, The University of Texas: Texas 2008. 
in Morocco.The selection process of the texts is described as well as the methods translation process and motivation to priorize Scope.

Keywords: Interculturality, rewriting, history, Talk of Darkness, Fatna El Bouih.

Sumario: 1. Introducción. 2. Metodología de traducción de Hadiz al- 'atma ("Relato de oscuridad"). 2.1. El proceso de documentación. 2.2. Las estrategias y técnicas de traducción. 3. Hadiz al- 'atma ("Relato de oscuridad"). 4. La noción de "oscuridad" en el contexto de los Años de Plomo. 5. Conclusión. 6. Referencias bibliográficas.

\section{Introducción}

En 2009, con el inicio de la implantación progresiva del Grado, el Área de Estudios Árabes e Islámicos de la Universidad Hispalense de Sevilla, adapta sus programas de estudios al nuevo marco docente europeo y se plantea ofertar un Máster de contenidos interculturales e interdisciplinares relacionados con el Mundo Árabe que no cubren los programas del área y que se consideran imprescindibles para la formación de post-grado. Uno de dichos programas a los que el Máster quería dar cabida era el titulado La memoria histórica de Marruecos: el fin de los Años de Plomo (1956-1999). Su objetivo principal era analizar la historia reciente de Marruecos, haciendo hincapié en los discursos oficial y no-oficial de las décadas de los años 70, 80 y 90, a través de documentación original en árabe e inédita en castellano. Los textos debían documentar la franja cronológica de la segunda mitad del siglo XX y estar considerados como referentes de la corriente literaria conocida en Marruecos como "Literatura de Testimonio" o de "Ruptura del Silencio".

La "Literatura de Testimonio" no es sólo la manifestación literaria de las víctimas de la represión de los Años de Plomo, sino también el ejercicio de su derecho a romper el silencio a través de la escritura (Berrada 2001: 33-45). Denuncia la voluntad institucional de dar cerrojazo a una de las páginas oscuras de la historia reciente de Marruecos, sin una reparación judicial de los hechos. Las víctimas (Torres 2007: 77-80) -sindicalistas, políticos, militares, resistentes, escritores, profesores, artistas, periodistas, entre otros gremios- fueron acusadas de haber atentado contra la seguridad del Estado y, bajo esa acusación, "hechos desaparecer"durante años, arbitrariamente. Los supervivientes que decidieron dejar constancia escrita de su cautiverio involuntario fueron, uno a uno, dando forma a este nueva manifestación literaria de denuncia, cuyo nacimiento está documentado en la década de los años 80, pero no será a partir del año 1999, con el fallecimiento de Hassan II, cuando alcance una dimensión internacional, con la publicación de la autobiografía de Malika Oufkir (Oufkir 1999), La prisonnière (Torres, 2006: 716-731), con la quedesveló al mundo los abusos de poder de Hassan II y su red de cárceles secretas, conocidos eufemísticamente, como "Los jardines del Rey"2. La

\footnotetext{
${ }^{2}$ Obra homónima, Les jardins du roi: Oufkir, Hassan II et nous, Michel Lafon: Paris 2000, escrita por su madre, Fatema Oufkir, esposa del General Oufkir, mano derecha de Hassan II. Oufkir llevó a cabo una 
entronización de su hijo, Mohamed VI, puso fin a la política institucionalizada de silenciar las voces de las víctimas y la libre publicación de estos testimonios en editoriales nacionales.

Dado que el número de testimonios registrado es relativamente elevado, así como el volumen de la documentación manejada -poemarios, correspondencia privada, autobiografías, obras de historia, diarios o cuadernos personales-establecimos comenzar por los testimonios de mujeres escritos en árabe, por ser los menos difundidos dentro y fuera del Mundo Árabe. El Estado marroquí, durante los Años de Plomo, defendió la inexistencia de presos políticos en el país y,especialmente, la de presas políticas. Enmascaró los casos de detenciones ilegales de mujeres, a las que registraba en el momento de su "desaparición" arbitraria e involuntaria con nombre de hombre, en el tiempo que permanecía en los centros de detención secretos. La doble circunstancia de ser retenida y despojada de su dignidad de mujer hizo que nos interesásemos por localizar estos testimonios autobiográficos (Torres 2010: 227-254).

Una de las autoras de mayor repercusión internacional es Fatna El Bouih gracias a sus obras Hadiz al- 'atma y Atlassiates, inéditas en castellano. Ambas fueron referencia documental para la publicación de un estudio monográfico, $L a$ ruptura del silencio. Testimonios (Torres 2010) que analiza los Años de Plomo bajo una perspectiva histórico-política desde el mayor número de perspectivas posibles.

La experiencia de Fatna El Bouih inspiró un cortometraje que ha sido presentado en diversos festivales e incluso galardonado con reconocimientos de la crítica cinematográfica ${ }^{3}$. Ha sido invitada como conferenciante por la Universidad de Austin, en Texas,la cual también se ha encargado de la edición de la versión en inglés de Hadiz al-'atma, Talk of darkness (2008), título que respeta literalmente el original en árabe. Previamente a esta traducción se realizó la versión francesa, Une femme nommée Rachid, en la que se privilegió la traducción intercultural del título que refleja la pérdida de dignidad identitaria sufrida por las "desaparecidas" políticas. Es relevante resaltar que este título es más elocuente para el público magrebí, por los motivos que hemos indicado más arriba.

La editorial marroquí Le Fennec, sita en Casablanca, responsable de la edición árabe y francesa de la obra que nos ocupa, creó la colección Brisons le silence. Témoinages (Rompamos el silencio. Testimonios) en la que han tenido cabida desde el año 2000, relatosy ensayos como el que nos ocupa en el presente estudio, Hadiz al- 'atma. Desde el año 2008, el Grupo de Investigación multidisciplinar "Escritoras y Escrituras (HUM 753)" de la Universidad Hispalense de Sevilla, en colaboración con esta última, inició gestiones para llevar a cabo la traducción íntegra de la obra. Ante la imposibilidad de poder llevar a buen puerto el proyecto, por cuestiones aje-

\footnotetext{
intentona golpista contra el monarca en el año 1972. En respuesta, Hassan II asesinó al general y mantuvo en cautiverio a toda su familia durante veinte años.

${ }^{3}$ Inspiró al realizador marroquí Rachid Kasmi el cortometraje-documental homónimo, proyectado en la tercera edición del FIDADOC (Festival international du film documentaire) de Agadir, la semana comprendida entre los días 9 y 13 de noviembre de 2010, y que fue galardonado, en el 2008, con el gran premio del jurado del Festival international du film documentaire de Casablanca.
} 
nas tanto a la editorial como a la universidad, optamos por utilizar la obra de manera parcial con fines documentales.

Hadiz al- 'atma, 2001 (Relato de oscuridad) / Une femme nommée Rachid(2002) / Talk of Darkness, 2008), en palabras de su propia autora, se define como un "testimonio-denuncia" (El Bouih 2001: 5) que recoge el relato autobiográfico de una experiencia trágica vivida y compartida por tres activistas políticas -Fatna El Bouih, Ouidad Baouab y Latifa Jbabdi- durante los meses de mayo a noviembre del año 1977: la "desapariciónarbitraria" en la cárcel secreta (Point fix) de Derb Mouley Chérif, conocida como La chambre noire (FDIH 2000: 4-6):

El proceso de las "desapariciones", según los informes de Amnistía Internacional y de las ONGpro-derechos humanos marroquíes e internacionales (Feliú, 2004: 153-5) ${ }^{4}$, estuvo en vigor durante los reinados de Mohamed V (1956-1961), de Hassan II (1961-1999) y parte del de Mohamed VI (1999-2002). El Ministerio del Interior, junto con sus servicios anexos, era el encargado de aplicar las directrices gubernamentales en materia de seguridad y mantenimiento del orden público y respeto a las instituciones. Contaba con la colaboración del Ministerio de Justicia, el majzen y, en última instancia, Palacio, representado en la figura del rey, máxima autoridad ejecutiva, al tiempo que espiritual.

Las víctimas de la "desaparición" sufrían una serie de vejaciones y maltratos inhumanos que, desde comienzos de los años 90 , se dieron a conocer al gran público, a raíz de la aparición de la obra de Gilles Perrault Notre ami le roi ${ }^{5}$, editado en España bajo el título Nuestro amigo el rey. Familiares, abogados, funcionarios de prisiones y algunas de las víctimas supervivientes decidieron romper el silencio narrando sus experiencias, recogidas en testimonios-denuncia, relatos autobiográficos o aportando cartas y documentación extraídas clandestinamente de las cárceles donde fueron recluidas ${ }^{6}$.

A finales de la década de los 90, Marruecos comenzó su proceso de transición política y de democratización haciendo gestos y dando muestras de querer poner fin a la impunidad institucional reinante durante el último medio siglo. Muchos ciudadanos marroquíes, por las condiciones internas del país -censura, falta de libertad de pensamiento, de expresión y de asociación- eran desconocedores de los abusos infligidos sobre algunos sectores de la sociedad marroquí incómodos a ojos del aparato

\footnotetext{
4 Morocco: "Disappearances" of People of Western Sahara Origin (Índice AI: MDE 29/17/90) y Marruecos: Detenciones politicas, “desapariciones” y torturas (Índice AI: MDE 29/01/91/s), publicado por AMNISTÍA INTERNACIONAL en 1990 y 1991; World Report 1992: Events of 1991, New York, Washington, DC., de HUMAN RIGHTS WATCH en 1992 y, finalmente, Country Reports on Human Rights Practices for 1999: Report submitted to the Committee on Foreign Relations US Senate and The Committee on Foreign Affairs US House of Representatives, Washington: US CPO, en el 2000, del Departamento de Estado de los EEUU.

5 Consúltese la bibliografía.

${ }^{6}$ La lista de obras catalogables en el género de "Literatura Carcelaria" testimonial o autobiográfica es extensa. Para tener una breve referencia sobre la misma, puede consultarse K. TORRES CALZADA, «Los rostros de la opresión de Khadija Menebhi: 1972-1982», Mujer en Dâr Al-Islâm, Sevilla, ArCiBel, 2007, 63-83 y, específicamente, de las páginas 77 a la 80.
} 
de seguridad del Estado (Torres 2007: 63-83; 2010: 51-119). Por esta razón, la traducción de los textos seleccionados respeta la propia intención de la autora (El Bouih 2001: 5 y 7):

Se trata de un testimonio-denuncia que arroja luz sobre los acontecimientos que forman parte de la historia contemporánea de Marruecos, que nos conduce a las criptas anónimas en las que sufrieron muchos jóvenes, hombres y mujeres, en Marruecos. Su pecado: rebelarse contra la confiscación de los sueños y sublevarse en defensa de su derecho a la dignidad y la libertad, por el cual pagaron un precio muy alto por el bien común [...] Este testimonio registra una etapa de la historia de las mujeres en el Marruecos contemporáneo y de su papel en la lucha política durante las últimas décadas del siglo XX. Es una semilla sembrada para germinar el recuerdo femenino documentado de la participación de las mujeres en la lucha por la defensa de los Derechos Humanos y, ante todo, por su derecho a la dignidad y a la libertad [...]Nos conduce al maltrato psicológico y a la violencia física que la presa política sufre, así como a los métodos de resistencia utilizados para mantenerse firme y conseguir, una vez superado todo ello, abarcar los aspectos de la realidad de las presas comunes y su terrible e inhumano sufrimiento.

Por la transcendencia internacional de Fatna El Bouih, centramos nuestro estudio en el enfoque sociocultural y desde la perspectiva de la interculturalidad con que se llevó a cabo la traducción de los fragmentos escogidos de Hadiz al- 'atma, para la elaboración del mencionado monográfico.

La Ruptura del silencio. Testimonios es un análisis documentado del fenómeno de las "desapariciones" sistemáticas en el Marruecos de los Años de Plomo, resultado de una iniciativa investigadora multidisciplinar que contó con la colaboración de diversos grupos de investigación de Humanidades andaluces y con la financiación de la Junta de Andalucía (IAC III/ 2009)7, tanto para la divulgación previa del proceso de documentación del mismo, a través de la selección de textos que presentamos en este artículo, como para su posterior publicación (Torres 2010).

El estudio se estructuró en cuatro capítulos sobre la historia política reciente de Marruecos, una conclusión y un anexo que incluye siete textos. Los tres primeros capítulos aportan toda la información documentada que requiere un estudio de investigación de estas características y cuyo destinatario es el gran público, prioritariamente y, en segundo lugar, el especializado. Llevamos a cabo una labor de divulgación a través de dos congresos internacionales, celebrados en Sevilla (2009) y en Salamanca (2010), dedicados a la figura de la autora, su obra y al valor documental de la misma en la reescritura de la historia de Marruecos ${ }^{8}$. El cuarto y últi-

\footnotetext{
7 Seminario La reescritura de la historia del Marruecos actual a través de sus mujeres y su divulgación: Bases para un diálogo intercultural, Universidad de Sevilla (16-18 de noviembre de 2009).

8 Ponencia de la Dra. Laila Carmen Mahmmoud Makki «Lectura de testimonios de Fatna El Bouih, traducidos del árabe al castellano y del francés al castellano, extraídos de su obra Atlassiates», Seminario $L a$ reescritura de la historia del Marruecos actual a través de sus mujeres y su divulgación: bases para un diálogo intercultural, 16, 17 y 18 de noviembre de 2009, Facultad de Filología de la Universidad de Sevilla. Comunicación mía titulada «Une femme nommée Rachid, Hamid, Touil, Dukkali... Máscaras de anulación,
} 
mo capítulo, titulado "El imperativo histórico: El fenómeno de las 'desapariciones' en Marruecos", recoge los testimonios de seis presas políticas, de los cuales, tres fueron traducidos del árabe al castellano: Fatna El-Bouih, Ouidad Baouab y Latifa Jbabdi, sin incluir el texto original árabe.

En el apartado "Hadiz al- 'atma",ofrecemos la versión bilingüe de los fragmentos relevantes correspondientes a la "desaparición" de Fatna El Bouih, que sirvieron para la reconstrucción de su estancia en la "Cámara negra", los sótanos de la comisaría de Derb Mouley Chérif, que dan significado al título de la obra.Estos fragmentos corresponden al capítulo primero 《Lerb [Mouley Chérif] o el sufrimiento" que constituye la aportación documental de la existencia de presas políticas en la célebre cárcel secreta.

\section{Metodología de traducción de Hadiz al-`atma ("Relato de oscuridad")}

De la lectura comprensiva de Hadiz al- 'atma determinamos optar por una metodología de traducción orientada hacia la comunicación y función del texto en la lengua de llegada, una vez que se hubo captado el sentido vehiculado por el texto. Seleccionamos los fragmentos correspondientes al capítulo primero, por ser los que documentaban la hipótesis de nuestra investigación y cuya traducción aportamos y analizamos más adelante. Del análisis de sus elementos macrotextuales y microtextuales, nos planteamos una hipótesis general de resolución de la traducción de elementos culturales, en concordancia con los principios de funcionalidad y equivalencia dinámica. Estimamos las necesidades extralingüísticas y de documentación que requería un texto de estas características, elaboramos el corpus documental que facilitase nuestra tarea traslativa y aplicamos las estrategias de traducción conforme a la metodología de traducción elegida, en función de la finalidad del texto en su contexto meta.

Dada la relevancia histórica de la obra, nosinteresaba transmitir la imagen conceptual cognitiva de la experiencia narrada que condensamos en la selección de textos que presentamos en estas páginas. Por ello, adoptamos el método traductor interpretativo-comunicativo,desde la perspectiva de la interculturalidad y haciendo hincapié en la función de la misma. La autora es emisora de un testimonio destinado a un público receptor, con un finconcreto. Igualmente, nuestro objetivo es doble: documentar unos acontecimientos históricos y elaborar un programa académico dedicado a la historia del Magreb.

Fatna El Bouih redacta su testimonio pensando en sus compatriotas como primeros destinatarios, de ahí que esté redactado en un árabe estándar, salpicado de usos dialectales propios de su zona de origen, la zona central de Marruecos y le con-

máscaras de entereza», VII Congreso Internacional del Grupo de Investigación Escritoras y Escrituras, Máscaras Femeninas: Retórica, simulación y espectáculo, 3, 4, 5 de noviembre de 2010, Facultad de Filología de la Universidad de Salamanca. 
cede al potencial público un papel fundamental en el proceso de lectura, dado que un elevado porcentaje de la población marroquí es analfabeta. El dariya o dialecto marroquí estándar es una lengua de transmisión oral, en proceso de sistematización de su escritura. El árabe estándar está al alcance de la población alfabetizada y que haya cursado estudios medios o superiores. La autora es consciente de esa circunstancia, por su condición de profesora de enseñanza secundaria.

En ella, se registran contrastes intralingüísticos con la intención de sumergir al lector en cada una de las circunstancias en las que se vio inmersa, al tiempo que hacerle partícipe de ellas. Esta circunstancia nos obligó a ser cuidadosos con el contenido y la metodología de exposición de nuestro estudio Ruptura del silencio. Testimonios. El texto original determinó la selección e inclusión de la información histórico-política del período en cuestión. Su traducción ha supuesto un ejercicio de reformulación de culturemas tales como: majzen (poder central establecido en función a una recaudación de tributos y lealtades pactadas) o nabshu fi-l-madi ("barrido del pasado", equivaldría a nuestra noción de Memoria histórica, pero con muchos matices), entre otras muchas, dado que no están insertadas en el canon cultural español desarrollado a lo largo de la historia. Por este motivo, se ha seguido un modelo de traducción de equivalencia dinámica, centrándonos en la transmisión del mensaje del texto origen al texto meta, con el fin de que la reacción del receptor meta, sea en esencia, la misma que la del receptor del texto original.

\subsection{El proceso de documentación}

Hadiz al- 'atma, por sus características macro y microtextuales, presenta necesidades documentales convencionales y singulares. Predomina el desarrollo de secuencias narrativas - descriptivas, expositivas, argumentativas y digresivas-, frente a las dramáticas, que posibilitan el despliegue temático y facilitan la traducción, dado que explicitan la información desconocida a la comunidad global de la lengua origen relativa a la cultura carcelaria, la violación de Derechos Humanos y a las condiciones que rodean las detenciones arbitrarias, como se refleja en este fragmento, en el que Fatna El Bouih describe un grado de tortura (Torres 2010: 123; El Bouih 2001: 17-18):

[...] ¿El tiempo? El tiempo no existía. No se diferenciaba la noche del día, todo era igual, incluida la tortura, para la cual no había un momento concreto, se infligía a cualquier hora, bajo cualquier forma y color, sin considerar el momento del día que fuese, ni el sexo de la víctima. El objetivo era destruir la identidad y el espíritu a través del cuerpo, ya fuese esa identidad la de un hombre o de una mujer. Todos viajamos en el "avión", suspendidos en el espacio de la muerte, con alambres eléctricos bajo las uñas, conocimos la 'falaqa' o 'colgamiento', una suspensión en el aire, el 'taalláq', en el argot del Derb, azotamiento de la planta de los pies, atados por medio de una cuerda al cuerpo suspendido con la cabeza en dirección al suelo. 


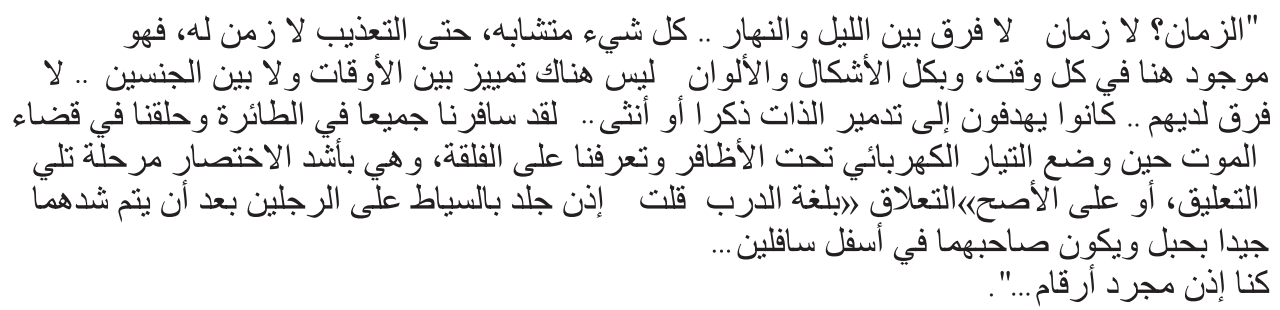

En el momento de abordar el borrador de la traducción, el proceso de documentación previa ${ }^{9}$-general y específica - estaba muy avanzado, dado que ya se contaba con un corpus de referencia tocante a los contextos histórico, político, social, jurídico-legal, lingüístico y relativo al fenómeno literario de la "Literatura carcelaria", que comprende toda la franja histórica de los Años de Plomo. Son documentos multilingües originales -árabe, francés- y paralelos -castellano-, divulgativos y especializados, que por orden de relevancia, se agrupan en:

\section{General:}

a. Gramáticas, manuales de estilo, diccionarios monolingües y bilingües.

b. Monografías sobre historia contemporánea de Marruecos.

c. Fuentes bibliográficas.

d. Recursos informáticos en internet.

Específica:

a.. Autobiografías

b. Artículos de investigación publicados en revistas nacionales e internacionales de impacto

c. Artículos de prensa diaria y semanal nacional (marroquí) e internacional (Mundo Árabe), en árabe y francés.

d. Informes oficiales de organismos internacionales pro Derechos Humanos (ONU, Amnistía Internacional, Fédération internationale des ligues des droits de l'homme, Humans Rights Watch)

e. Correspondencia privada publicada en monografías, testimonios, en webs oficiales de asociaciones de víctimas de los Años de Plomo.

f. Entrevistas concedidas por las víctimas y familiares a los medios de comunicación.

\footnotetext{
9 Torres CAlzadA, K., «Une femme nommée Rachid ... Hamid, Touil, Dukkali...: máscaras de anulación-máscaras de entereza», en ARRIAGA, M., (ed.) Máscaras femeninas, Sevilla: ArCiBel, 2010, 227-254. De la misma autora, «Los rostros de la opresión de Khadija Menebhi: Marruecos 1972-1982», Mujer en Dâr Al-Islâm, Colección Estudios Árabes e Islámicos 2, Sevilla, ArCiBel, 2007, 63-83 y «La prisonnière: El harén de Hassan II según la mirada de Malika Oufkir y la pluma de Michèle Fitoussi», en: ARRIAGA, M. (ed.) Mujeres, espacio \& poder. Sevilla: ArCiBel 2006, 716-731.
} 
Gracias a su idoneidad y especificidad con respecto a la información transmitida en el relato, así como por su originalidad, exhaustividad y fiabilidad, se pudo vehicular las estrategias de traducción con las técnicas traslativas que se aplicaron, especialmente, en el análisis estructural del texto de cara a obtener el grado máximo de comprensión inferencial, en la fase onomasiológica:

"Los inspectores eran también dos hombres. Comprendí por sus preguntas que estaba acusada de haber cometido delitos graves y que, según ellos, siendo estudiante debería haberme limitado a estudiar y a no meter las narices donde no me llamaban, pero al meterme donde no debía, me esperaba mi merecido. (Torres 2010: 122)

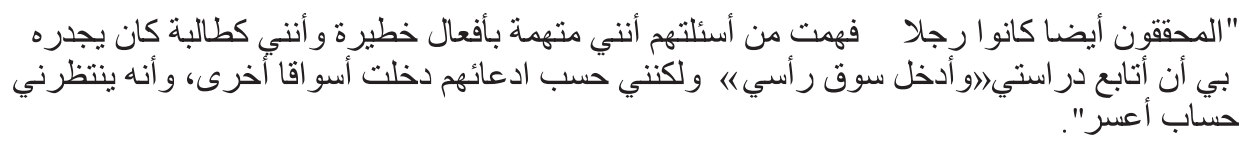

(El Bouih 2001: 13)

En clara referencia a los siete grados de tortura que le iban a infligir a lo largo de su prolongada estancia en la "Chambre noire".

El punto de partida en el proceso de documentación viene marcado por dos tipos de textos paralelos editados originalmente en francés ${ }^{10}$ y un informe oficial de la Fédération internationale des ligues des droits de l'homme (FDIH) sobre las "desapariciones forzadas". El precursor fue la investigaciónde carácter histórico y político con fines de denuncia del régimen de Hassan II Notre ami le roi de Gilles Perrault (1991), publicada en castellano bajo el título Nuestro amigo el rey (1991), cuya aportación es de carácter tanto contextual como terminológica. Le sigue la autobiografía La prisonnière (1999) de Malika Oufkir, primogénita del malogrado Mohamed Oufkir, con cuyo testimonio y el de su madre, aparecido un año después, Les jardins $d u$ roi, se destapó la red de cárceles clandestinas del régimen. En tercer lugar, relevante papel desempeñó el informe $\mathrm{n}^{\circ} 298$ de la Mission internationale d'enquête de la Fédération internationale des droits de l'homme, publicado en noviembre de 2000, bajo el título "Les disparitions forcées au Maroc: répondre aux exigences de vérité et justice" (FDIH 2000: 1-16), donde se detalla el proceso de las "desapariciones forzadas" y la violación de las libertades públicas en Marruecos desde 1973 hasta 1999.

Posteriormente, se analizaron los textos paralelos dedicados exclusivamente a Derb Mouley Chérif escritos por presos hombres (Mdidech 2000) y los artículos publicados en revistas científicas por los abogados defensores de los mismos, entre los que destaca los elaborados por el abogado marroquí Abderrahim Berra-

${ }^{10}$ Se puede consultar una lista de las obras más representativas de la Literatura Carcelaria en "Los rostros de la opresión de Khadija Menebhi”, op.cit., 77-80.intentona golpista contra el monarca en el año 1972. En respuesta, Hassan II asesinó al general y mantuvo en cautiverio a toda su familia durante veinte años. 
da, quien representó a muchos de las víctimas de las exacciones del régimen marroquí.

\subsection{Las estrategias y técnicas de traducción}

En la fase de lectura comprensiva,analizamos el texto seleccionado aplicando nuestras competencias lingüística y documental (Hymes 1971), con el fin de determinar la vía traductológica más idónea. Considerando las características del mismo, determinamos, como ya adelantamos, que la vía traslativa comunicativa-funcional era la más apropiada (Le Poder 2006: 1975-1980).La traducción comunicativa requiere un alto grado de penetración en el contenido del texto origen, de ahí, que aplicáramos técnicas traductológicas que reflejasen, en el texto meta, la función y finalidad del texto origen, sin que tuviera que asemejarse a aquél (Le Poder 2006: 1979).

Del análisis textual a nivel pragmático, semántico y formal, inferimos los tipos de problemas lingüísticos, a los que debíamos dar solución, así como las estrategias y técnicas que debían ser adoptadas y aplicadas. En general, los problemas que mayor dificultad de resolución presentaron fueron los lingüísticos, no siendo así, los extralingüísticos, los instrumentales ni los pragmáticos.

Considerando la macroestructura, estamos ante un texto narrativo testimonial, redactado en un árabe estándar formal y salpicado de referencias dialectales. De las microestructuras, analizamos los marcadores del discurso en su función inferencial, las asimetrías cualitativas y cuantitativas, los mecanismos de cohesión textual, el contraste morfosintáctico entre el árabe estándar y el castellano y, por último, las variaciones lingüísticas dialectales, idiolectales y de jerga que, de manera consciente y apartándonos del principio de la equivalencia funcional, hemos decidido no traducirpor no considerarlas relevantes para el fin perseguido.

Siguiendo el enfoque discursivo y funcional, se aplicaron algunas de las técnicas que destacamos a continuación, sin pretender ser exhaustivos en nuestra descripción (Hurtado Albir 2001: 256-261):

- Transposición: cambios gramaticales.

a. "Hacia las tres de la tarde llamé a la puerta de la casa de mi amiga que vivía en $L^{\prime}$ Océan, en Rabat".

$$
\text { " كانت الساعة تشير إلى الثالثة بعد الزوال حين طرقت باب منزل صديقتي بحي المحيط بالرباط". }
$$

En primer lugar, sustituimos el verbo كانت del texto origen por la preposición "hacia" con valor temporal, en el texto meta y, en el segundo caso, sustituimos una preposición que acompaña a un sustantivo en el texto origen بحي ("en el barrio"), por el verbo "vivía", en el texto meta. 
b. "Así comienza la historia de un secuestro que durará cinco años..."

$$
\text { "كانت هذه بداية حكاية الاختطاف التي ستدوم خمس سنوات.." }
$$

A continuación, sustituimos el verbo كانت que inicia la frase, por el adverbio de modo "Así" y el nombre بداية por la forma del verbo "comenzar" en presente de indicativo.

c. "[...] Me vendaron los ojos y me condujeron en coche a toda velocidad. No era la única que se encontraba allí. Me percaté de ello cuando mi cuerpo rodaba como un cordero en el interior, de un lado a otro, debido a que quitaron los asientos, y llegaba a chocar, a veces, con algo vivo, que quizás corría la misma suerte que yo".

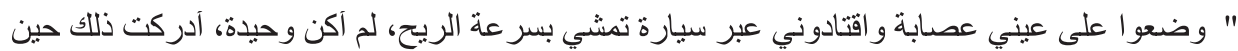

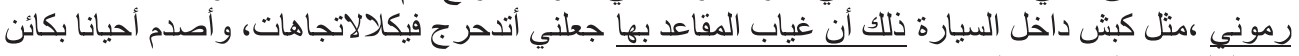
حي لعله كان يلقى نفس المصير .." السيارة

Se efectúa el cambio gramatical del deíctico ذلك que introduce una oración nominal, por la forma de participio con valor causal, "debido a".

- Compensación: alteración del orden oracional para mantener la coherencia.

“... el amigo que iba conmigo, huyó al intuir que la casa estaba ocupada. Uno de los que estaba dentro salió como una flecha tras él y le disparó en el muslo para detenerlo. De regreso, mi amigo traía la ropa desgarrada. Eran dos agentes de la policía secreta de paisano y armados. Uno llevaba la pistola en el cinturón, el otro, que la llevaba enfundada debajo del sobaco, me apuntó a la cara en dos ocasiones".

$$
\begin{aligned}
& \text { "،هرب صديقي الذي كان بر افقني حين شعر أن المنزل محتل فلاحقه أحدهم، انطلق كالسهم وراءه إناه }
\end{aligned}
$$

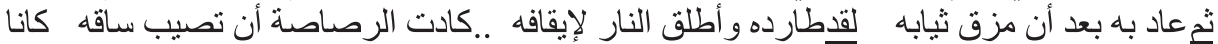

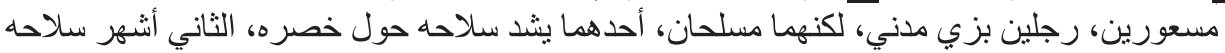

$$
\begin{aligned}
& \text { في وجهي مرتين .كان يخفيه تحت إبطه ". }
\end{aligned}
$$

Se altera el orden oracional del texto origen, en el texto meta, para mantener la coherencia semántica. La partícula coordinante 3 , que en árabe estándar funciona como marcador coordinante con matiz semántico temporal de posterioridad, nos permite trasladar la oración que introduce, al final del párrafo, como última acción de la sucesión. En el texto origen, aparece en mitad del párrafo, seguida de una oración introducida por la partícula لقد, , partícula que indica, claramente, la anterioridad de la acción verbal que introduce. 


\section{- Reducción:}

a. “¿El tiempo? El tiempo no existía. No se diferenciaba la noche del día, todo era igual, incluida la tortura, para la cual no había un momento concreto, se infligía a cualquier hora, bajo cualquier forma y color, sin considerar el momento del día que fuese, ni el sexo de la víctima”.

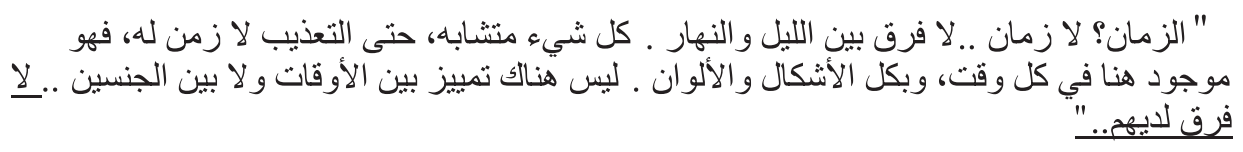

Omitimos su traducción, para no ser redundantes, dado que iniciamos el párrafo con "No se diferenciaba la noche del día, todo era igual...".

b. "El "avión" consistía en una crucifixión a la marroquí. La persona es transformada en un cordero o un pollo sobre el fuego que no es otra cosa que los latigazos que se reciben, primero, en la planta de los pies y, después, por todo el cuerpo. Con la planta de los pies en alto y la cabeza hacia abajo, continúan los latigazos mientras te interrogan sobre nuestras actividades, conversaciones, reuniones y todo lo que concerniente a nuestra persona".

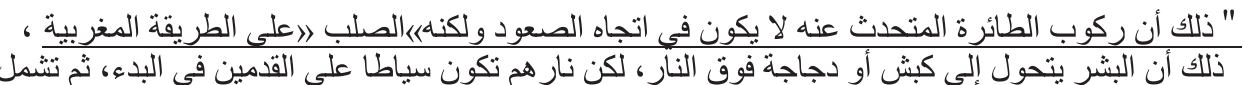

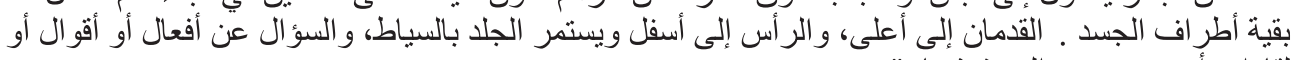

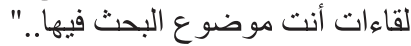

En "El 'avión' consistía en una crucifixión a la marroquî" se han suprimido reiteraciones semánticas relativas a la idea de ascenso en el aire e e ركوب|الصعود que se sobreentiende por la posterior explicación que da la autora.

\section{- Adaptación:}

“[...] ¿En qué lugar? No era un lugar concreto. Era una especie de "corredor" largo en el que había tres habitaciones sin otro mobiliario que los detenidos, mejor dicho, "desaparecidos". Ninguno de los que estaban allí recibió una orden de detención. Tenían los pies cubiertos de heridas y las muñecas encadenadas".

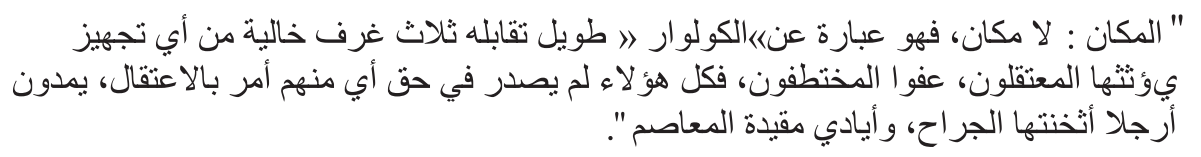

Hemos adaptado el elemento cultural «بكوميسارية 》 -"comisaría”- por el de calabozo, más neutro, con lo que hemos suprimido la connotación negativa que le da la autora, dado que en la cultura meta, el sentido de calabozo de comisaría, en la actualidad no es el mismo que en la década de los setenta, en ambas culturas. 


\section{- Préstamo:}

"Todos viajamos en el "avión", suspendidos en el espacio de la muerte, con alambres eléctricos bajo las uñas, conocimos la 'falaqa' o 'colgamiento', una suspensión en el aire, el 'taalláq', en el argot del Derb, azotamiento de la planta de los pies, atados por medio de una cuerda al cuerpo suspendido con la cabeza en dirección al suelo".

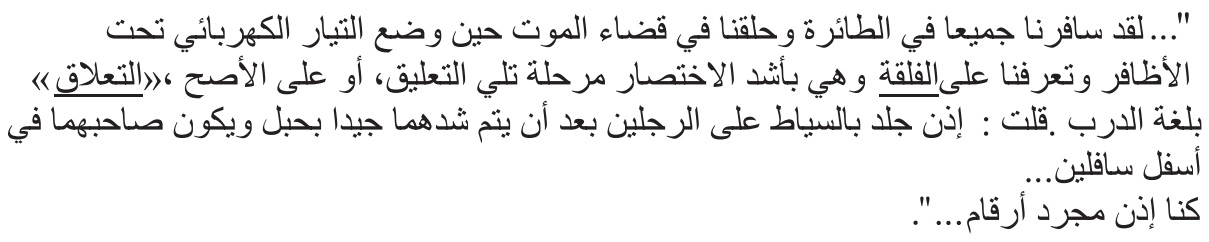

Integramos los términos falaqa y taalláq del argot del Derb tal cual, para marcar la particularización de su uso y su connotación semántica, referentes a una de las siete grados de tortura institucionalizados en esta comisaría.

Junto a estas técnicas de traducción, se aplicaron elisiones deícticas y referenciales, variaciones, compensaciones lingüísticas con fines expresivos, así como generalizaciones y modulaciones de las voces verbales, con vistas a mantener la cohesión, la coherencia y la progresión temática.

\section{Hadiz al-`atma ("Relato de oscuridad")}

Este relato autobiográfico coral, inédito en castellano, estructurado en diecisiete capítulos, narra el periplo de tres presas políticas marroquíes por las cárceles clandestinas y civiles del país, durante los Años de Plomo. Describe el proceso de detenciones arbitrarias que se iniciaba en el calabozo de Derb Mouley Chérif, donde fue torturado todo opositor político, ideológico y religioso al régimen o a la monarquía.

A continuación, incluimos la selección de fragmentos extraídos del capítulo primero, titulado "El Derb o el relato de los sufrimientos", referente a las prácticas del Derb contra las presas políticas que documentaron nuestra investigación (El Bouih 2001: 10-26/ Torres 2010: 121-125) y que fueron traducidos del árabe al castellano:

"Hacia las tres de la tarde llamé a la puerta de la casa de mi amiga que vivía en L'Océan, en Rabat. Me sorprendió al abrirse la puerta. A través de la apertura una mano extraña me arrastró con fuerza hacia dentro, el amigo que iba conmigo, huyó al intuir que la casa estaba ocupada. Uno de los que estaba dentro salió como una flecha tras él y le disparó en el muslo para detenerlo. De regreso, mi amigo traía la ropa desgarrada. Eran dos agentes de la policía secreta de paisano y armados. Uno llevaba la pistola en el cinturón, el otro, que la llevaba enfundada debajo del sobaco, me apuntó a la cara en dos ocasiones. Así comienza la historia de un secuestro que duraría cinco años". 


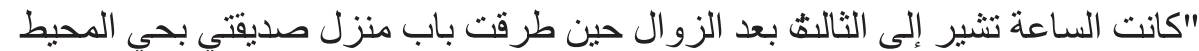

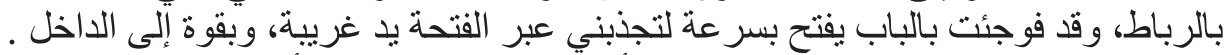

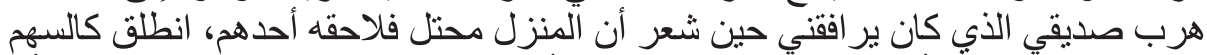

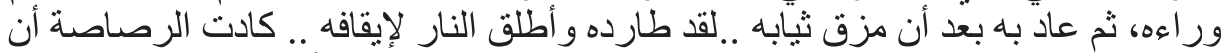

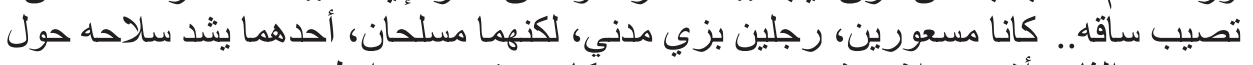

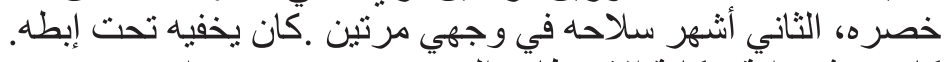

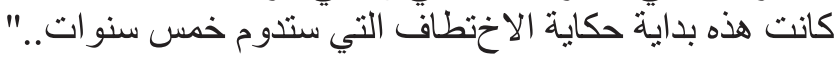

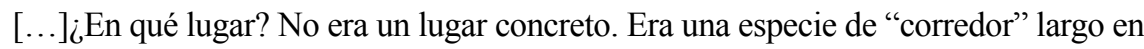
el que había tres habitaciones sin otro mobiliario que los detenidos, mejor dicho, "desaparecidos". Ninguno de los que estaban allí recibió una orden de detención. Tenían los pies cubiertos de heridas y las muñecas encadenadas. Me uní a ellos dos días después de mi secuestro y de que me confinaran en el calabozo de Place Pietri [en el centro de Rabat], donde me declararon elemento peligroso, por lo que recibieron órdenes de aislarme. Los desaparecidos eran todos hombres.

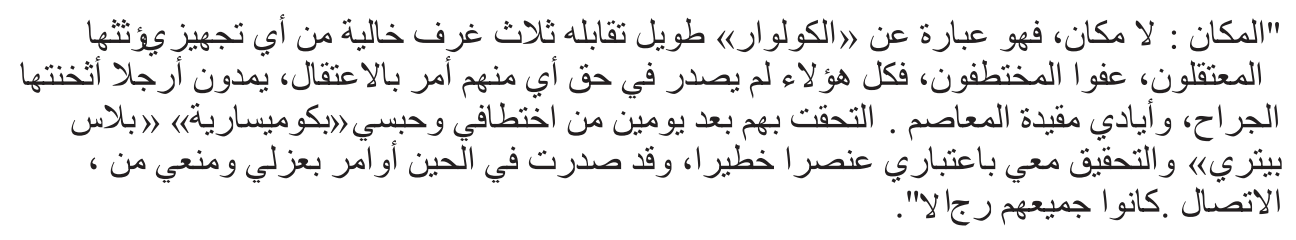

Los instantes de silencio eran interrumpidos por el frenazo de un coche que se paró ante la puerta de la casa. ¿Quién era ese visitante? Nos ordenó que nos mantuviésemos en silencio y en total calma. Uno de los vigilantes nos condujo al coche clandestinamente. Lo extraño del asunto es que el coche no tenía conductor. ¿Dónde se escondía? Fuimos trasladados en secreto y cuando nos enterrasen, todo habría acabado.

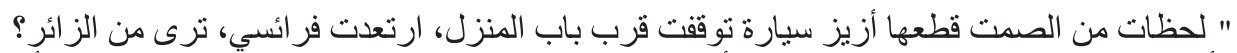

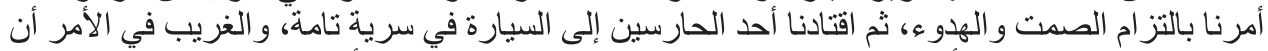

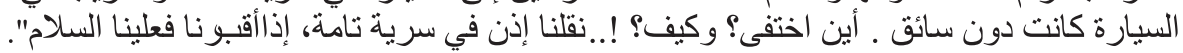

Los inspectores eran también dos hombres. Comprendí por sus preguntas que estaba acusada de haber cometido delitos graves y que, según ellos, siendo estudiante debería haberme limitado a estudiar y a no meter las narices donde no me llamaban, pero al meterme donde no debía, me esperaba mi merecido.

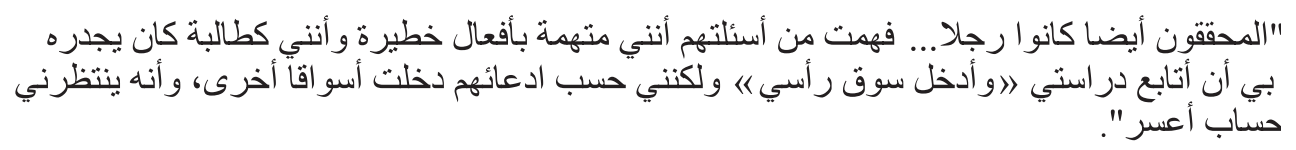

[...] Me vendaron los ojos y me condujeron en coche a toda velocidad. No era la única que se encontraba allí. Me percaté de ello cuando mi cuerpo rodaba como 
un cordero en el interior, de un lado a otro, debido a que quitaron los asientos, y llegaba a chocar, a veces, con algo vivo, que quizás corría la misma suerte que yo. Pasadas varias horas de trayecto, llegamos a un lugar del que nunca había oído hablar".

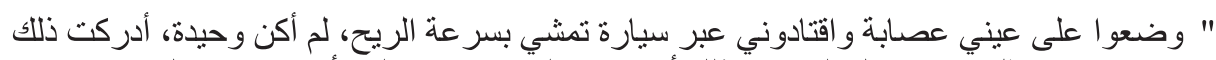

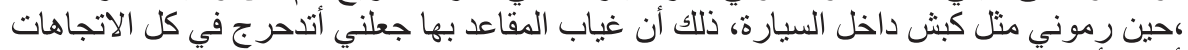

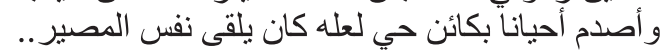

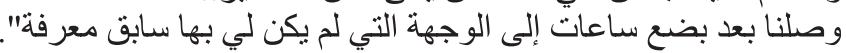

“[...] No me podía creer que estuviese ante el 'responsable', el 'jefe', el 'muallem', la autoridad del gobierno. ¡Ay, Dios mío! ¿A quién le has delegado tu poder en este país? Me dio un número y un nombre de hombre, Rachid. 'Ni te muevas ni hables, salvo cuando escuches tu nombre, Rachid'. Este fue el inicio de la anulación de mi identidad, el secuestro y la detención arbitraria; después, vino la anulación de mi feminidad al tratarme como si yo fuese un hombre llamado Rachid".

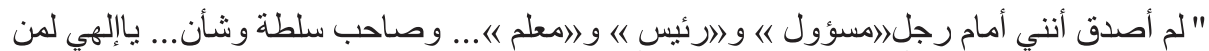

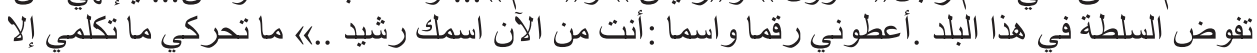

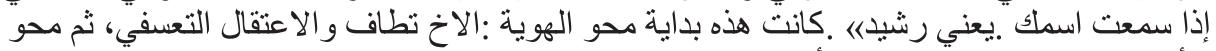

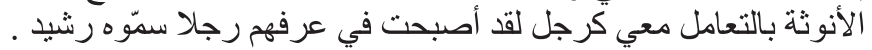

“[...] ¿El tiempo? El tiempo no existía. No se diferenciaba la noche del día, todo era igual, incluida la tortura, para la cual no había un momento concreto, se infligía a cualquier hora, bajo cualquier forma y color, sin considerar el momento del día que fuese, ni el sexo de la víctima. El objetivo era destruir la identidad y el espíritu a través del cuerpo, ya fuese esa identidad la de un hombre o de una mujer. Todos viajamos en el "avión", suspendidos en el espacio de la muerte, con alambres eléctricos bajo las uñas, conocimos la 'falaqa' o 'colgamiento', una suspensión en el aire, el 'taalláq', en el argot del Derb, azotamiento de la planta de los pies, atados por medio de una cuerda al cuerpo suspendido con la cabeza en dirección al suelo".

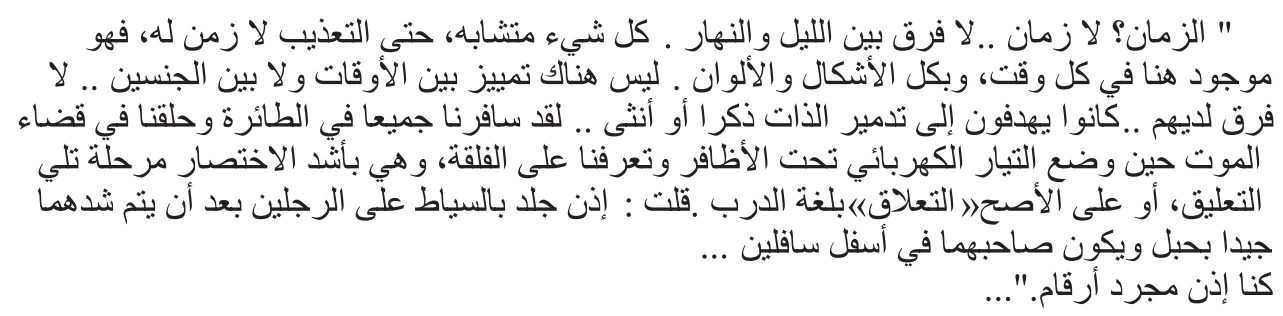

"El "avión" consistía en una crucifixión a la marroquí. La persona es transformada en un cordero o un pollo sobre el fuego que no es otra cosa que los latigazos que se reciben, primero, en la planta de los pies y, después, por todo el cuerpo. Con la planta de los pies en alto y la cabeza hacia abajo, continúan los latigazos mientras te interrogan sobre nuestras actividades, conversaciones, reuniones y todo lo que concerniente a nuestra persona. Eso era la 'falaqa' o, al menos, lo que 
conocí de ella, ya que, por desgracia o por fortuna, perdí la consciencia tras los primeros golpes e ignoro qué sucedió después. Digo, por desgracia, ya que, al estar inconsciente, se veían obligados a repetir la misma operación varias veces. Ellos no paraban por un momentáneo sentimiento de compasión hacia mí o porque temieran por mi estado de salud, sino movidos por la información que esperaban obtener, que los mantenía en ascuas". Éramos simples números. Nos tuvieron en estas condiciones siete meses".

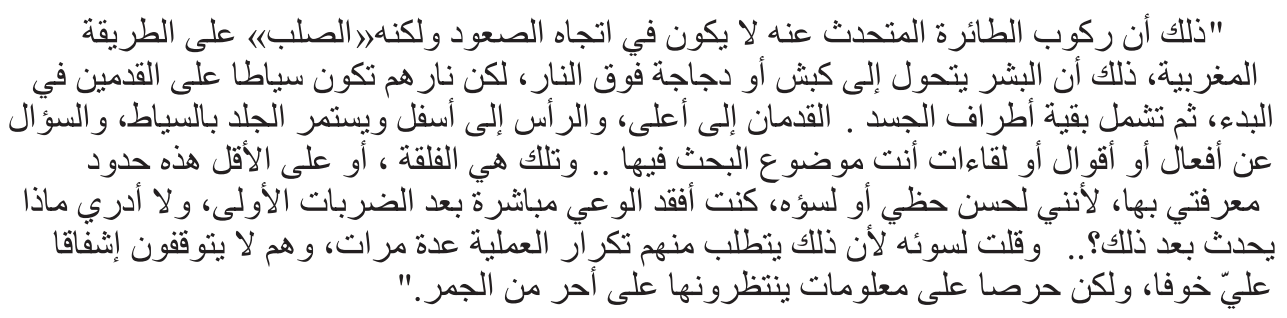

“[...]Los primeros días de arresto en el centro de detención eran insoportables. El confinamiento en el calabozo era cada vez más opresivo y humillante. Estés el tiempo que estés no llegas a acostumbrarte. Nunca vi, en mi amado país, un sistema más eficaz que éste, tan rápido a la hora de secuestrar e investigar, adelantándose a que los acontecimientos tuviesen lugar, 'cocinando' los casos y 'montando' las escenas del crimen. Los gritos y lamentos de los torturados amueblaban de pánico el espacio. 'La muerte me sucumbía con sus idas y venidas', como dijo el poeta. Cuando uno de ellos me puso la pistola en la sien, me dijo fuera de sí: ¡Te voy a matar, te voy a enterrar!'. Sentí que realmente iba a hacerlo y comencé a temer por un destino incierto. Esa actividad rabiosa y constante me mantenía siempre nerviosa e insomne. Perdí el sueño y la tranquilidad debido a la intranquilidad y la inseguridad que sentía mi cuerpo".

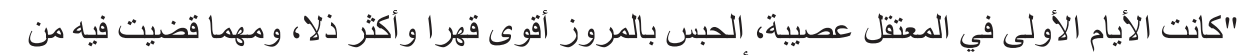

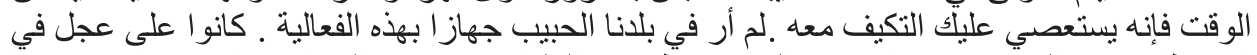

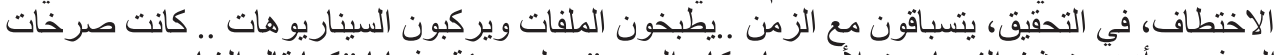

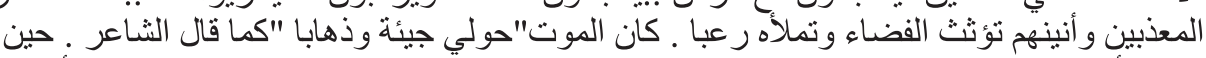

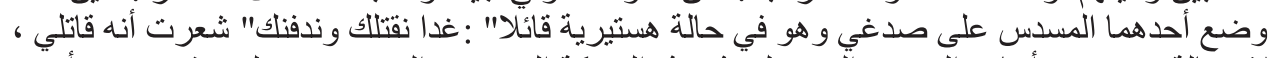

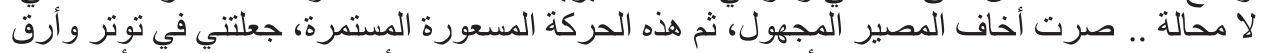

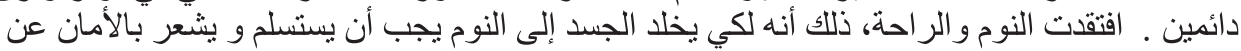
هذا اللامكان . دين

“[...]Quizás los muros de esa prisión fueron testigos, en toda su historia, de los primeros gritos de protesta, que, curiosamente, eran gritos de mujeres. Me armé y me pertreché de toda mi fuerza para defenderme. Determiné las dimensiones del lugar. En verdad, comprendí, desde mi 'cara a cara' con el 'muallem' Youssfi Kaddour, que yo era huésped de Moulay Derb Chérif, conocido actualmente como Derb y que yo integraba la centena de estudiantes y otros que estuvieron incluidos en la campaña de secuestros arbitrarios, irrumpiendo en las casas en busca de un esposo, de un hermano o de un amigo". 


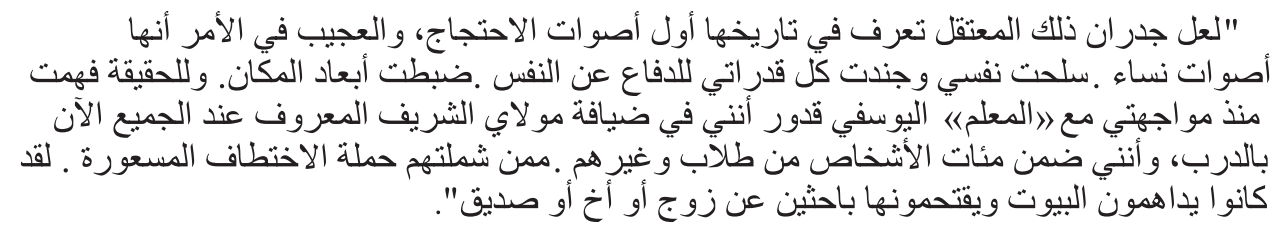

“[...] En las primeras semanas nos uníamos en la humillación, en el abuso y en la tortura,de manera continuada Maria Zouini, Ouidad Baouab, Latifa Jbabdi y, más tarde, Nguia Boudaa. Éramos consideradas menos que animales y acostumbrarnos a esta situación exigía de nosotras un esfuerzo terrible de adaptación. Conseguí acercarme a mis compañeras, a pesar de la estrecha vigilancia y del férreo control, y establecer vínculos entre nosotras. Nos conocimos a través del silencio y la oscuridad, en la prohibición de hablar y bajo el ojo vigilante del torturador. Nuestros dedos, con destreza y cautela indescriptibles escribían sobre las sienes los más maravillosos relatos y chistes. Nuestros dedos se convirtieron en lápices y nuestros costados en hojas de papel. En esos momentos robados reducíamos la vida a gestos y signos, sólo comprensibles entre nosotras y creados únicamente por nosotras. Las agresiones que sufrimos fueron violentas durante toda la detención secreta y la sufrimos en un grado más extremo por ser mujeres".

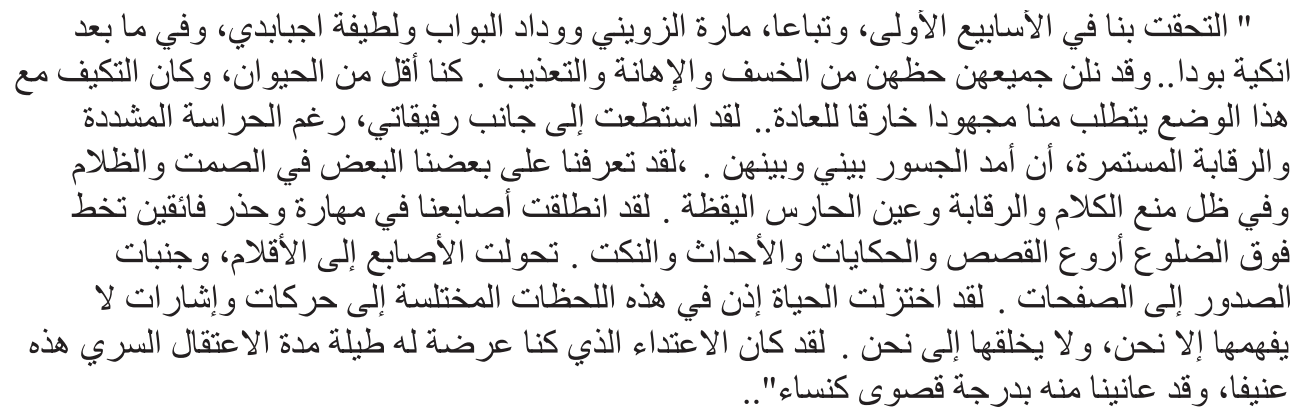

“[...] Éramos víctimas de la desprotección legal, de manera clara y deliberada. A diferentes formas de tortura y maltrato se le añadían las violaciones a la justicia. Nos llevaron ante el juez instructor, en condiciones que, como mínimo, pueden calificarse de detención secreta o ilegal. Entramos en sótanos oscuros y antiguas criptas que inspiraban posibilidades e imágenes diferentes. Hasta que no nos sacaron de allí no nos dimos cuenta de que era el Tribunal de Apelación. La vigilancia era férrea. Las manos las teníamos atadas a la espalda, no nos despojaron de las vendas que llevábamos en los ojos hasta que comparecíamos ante el juez instructor, para volver a ponérnosla en cuanto salíamos de la sala. [...]"

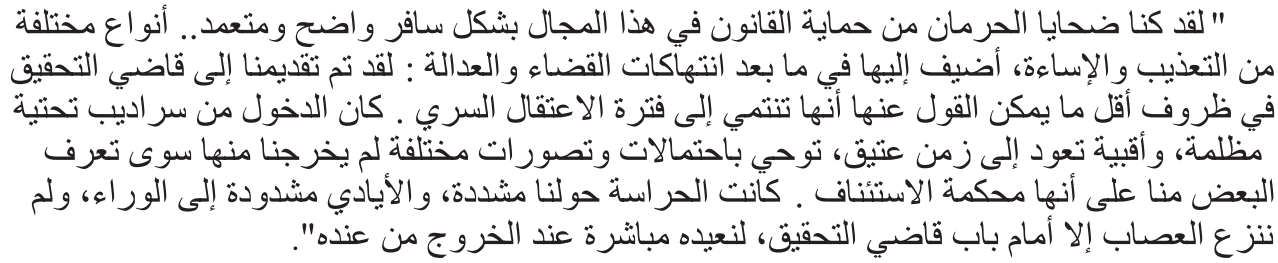


"De esta forma abandonamos el centro de detención al amanecer, aquel día sin ningún aviso previo de nuestro traslado ante el juez de instrucción y, acto seguido, ante el procurador del rey. Así, por primera vez, vi la luz y sentí que recordaba mi identidad"

$$
\begin{aligned}
& \text { "هكذا إذن غادرنا المتعقل في الفجر ذات يوم ودون سابق إنذار، لنحال على قاضي التحقيق، ثم }
\end{aligned}
$$

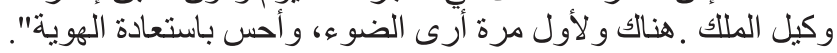

\section{La noción de "oscuridad" en el contexto de los Años de Plomo}

Como se ha podido comprobar de la lectura del apartado anterior, nuestra traducción se centra en transmitir el sentido y la esencia de la obra original. Esta selección se corresponde con la experiencia vivida por la autora en "La habitación negra". La noción de "oscuridad" ( 'atma), en este contexto, es sinónimo de "detención arbitraria" prolongada en el tiempo, en Derb Mouley Chérif, donde los detenidos permanecen meses con los ojos vendados y esposados con grilletes, incluso durante las sesiones de tortura. Esa oscuridad es identificada por varias generaciones de marroquíes con la impunidad de una dinastía reinante y un sistema de opresión centralizado ejercido contra los sectores sociales que el régimen consideraba un peligro para la seguridad del Estado -sindicalistas y políticos de izquierdas, islamistas, intelectuales, docentes, artistas, escritores y estudiantes-. Esa opresión, dentro del Derb ha sido experimentada en las siguientes etapas de sufrimiento:

Retención arbitraria

Colapso físico

Humillación

Violación

Violencia física

Amenazas

Descargas eléctricas

Azotamiento, apaleamiento

Confinamiento

Aislamiento

Sufrimiento

Anulación de la identidad

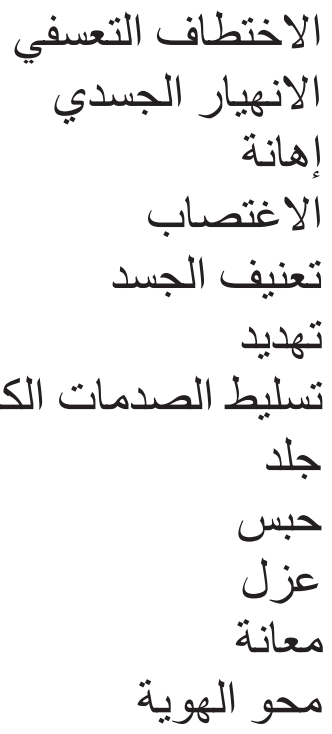

Fatna El Bouih condensa en unas pocas páginas su experiencia de siete meses en el centro de tortura clandestino del Derb, a través de las cuales expresa los procesos psicológicos de defensa, los diferentes estados de ánimos por los que pasó, las sen- 
saciones y las reflexiones íntimas, primando el uso de categorías nominales con valor de acción verbal -los "másdares", equivalentes a los infinitivos-, para plasmar la sensación de "atemporalidad prolongada" del sufrimiento. Consigue transmitir la claustrofobia, la angustia, el pánico, la levedad del ser, al tiempo que el instinto de supervivencia y el vencimiento al miedo.

\section{Conclusión}

Sumamente interesante se antoja el análisis de la obra desde el enfoque lingüístico, por las variantes diafásicas, diastráticas y diatópicas, las realizaciones del argot carcelario que registra, así como los términos relativos a las diversas técnicas de torturas, los culturemas y los realia vinculados a diversos ámbitos de la realidad marroquí de la etapa conocida como "Los Años de Plomo", las desapariciones arbitrarias, las cárceles secretas y el funcionamiento del sistema judicial, entre otros.

La peculiaridad idiomática que presenta esta obra nos permitió desarrollar estrategias que compensaran ciertas dificultades gramaticales, sociolingüísticas o discursivas, tal y como se ha esbozado en el apartado dedicado a la metodología. El árabe estándar y su realización dialectal presentan muchas diferencias con respecto al castellano en la categorización conceptual y gramatical, en la tipología sintáctica de la lengua, en la combinatoria léxica y en los modos de introducción del estilo directo e indirecto, por citar sólo algunas.

La traducción ofrecida en estas páginas refleja la necesidad de un aparato crítico considerando los contrastes diatópicos, culturales, históricos, económicos y sociales que separan a ambos países.

\section{Referencias bibliográficas}

\section{Documentación}

AMNISTÍA INTERNACIONAL, «La exclusión de los menores de la pena de muerte con arreglo al derecho internacional general», (18/07/2003), 1-30 (AI INDEX: ACT 50/004/2003).

AMNISTÍA INTERNACIONAL, Informe 1991. EFAI: Madrid 1991.

Berrada, A., «La defensa de la impunidad», Nación Árabe 45, Año XV (Verano, 2001), $33-45$.

El BOUIH, F., Talk of Darkness. Translated from the Arabic and introduced by Musthapa Kamal and Susan Slyomovics, The Center for Middle Eastern Studies. The University of Texas: Texas 2008.

EL BOUIH, F., Hadiz al- 'atma. Al-Fanak: Dar al-Baida 2001.

FDIH, «Les disparitions forcées au Maroc: répondre aux exigences de Vérité et Justice», 298 (2000), 1-16.

Feliú, L., El jardín secreto. Los defensores de los derechos humanos. Libros de la Catarata: Madrid 2004.

HumANS RIGHTS WATCH, World Report 1992: Events of 1991. New York / Washington, DC: Humans Rights Watch 1992. 
InSTANCE EQUité ET ReCONCILIATION, Instancia Equidad y Reconciliación (7 enero 2004-30 noviembre 2005). Agadir: IER 2005, 1-30.

MDIDECH, J., La Chambre noire ou Derb Mouley Chérif.Casablanca: Eddif 2000.

ONU (Comité de DD.HH.), Pacto Internacional de Derechos Civiles. Examen de los informes presentados por los Estados partes en virtud del artículo 40 del Pacto. Quinto informe periódico. Marruecos (10 de marzo de 2004), 1-46.

OufkiR, M. / Fitoussi, M., La prisonnière. París: Éditions Grasset \& Fasquelle 1999.

OUfKIR, M., La prisionera. Barcelona: Modadori 1999.

Perrault, G., Notre ami le roi. París: Gallimard 1990.

Perrault, G., Nuestro amigo el rey. Barcelona: Plaza y Janés / Cambio 161991.

Torres Calzada, K., «Une femme nommée Rachid ... Hamid, Touil, Dukkali...: máscaras de anulación-máscaras de entereza», en Arriaga, M. (ed.), Máscaras femeninas. Sevilla: ArCiBel 2010, 227-254.

Torres CAlzadA, K., «Los rostros de la opresión de Khadija Menebhi: Marruecos 19721982», Mujer en Dâr Al-Islâm. Colección Estudios Árabes e Islámicos 2. Sevilla: ArCiBel 2007, 63-83.

Torres CAlzadA, K., «La prisonnière: El harén de Hassan II según la mirada de Malika Oufkir y la pluma de Michèle Fitoussi», en: ArRiAgA, M. (ed.), Mujeres, espacio \& poder. Sevilla: ArCiBel 2006, 716-731.

\section{Traductología}

Albaladejo Martínez, J. A., «Literatura y literatura traducida», Estudios de Traducción 1 (2011), 73-84.

ElEnA, P., «Bases para la comprensión organizativa», Revista de Lingüística y Lenguas Aplicadas 6, 2 (2011), 125-137.

ElENA, P., «La documentación en la traducción general», La enseñanza de la traducción. Castellón de la Plana: Universitat Jaume I D.L. 1996,79-90.

Gonzalo García, C. / García Yebra, V. (eds), Manual de documentación y terminología para la traducción especializada. Madrid: ArcoLibros 2004.

Hymes, D. H., On communicative compentence. Filadelfia: University of Pennsylvania Press.

Hurtado Albir, A., Traducción y Traductología. Madrid: Cátedra 2001.

HuRTADO AlBIR, A., «La traductología: lingüística y traductología», TRANS, 1 (1996), 151160.

HurTado AlbiR, A., La enseñanza de la traducción. Castellón de la Plana: Universitat Jaume I D.L. 1996.

Le Poder, M.-E. D., «Discurso y traducción», Actas del I Congreso Internacional del Análisis del Discurso: lengua, cultura, valores. Madrid: ArcoLibros 2006, 1975-1980.

LOUREDA LAMAS, O., «Marcadores del discurso, pragmática experimental y traductología: horizontes para una nueva línea de investigación», Pragmalingüística, 18 (2010), 74 107.

Plassard, F., Lire pour traduire. Les Presses de la Sorbonne Nouvelle: Paris 2007.

PortolÉs, J., Marcadores del discurso. Barcelona: Ariel 2001 [1998].

Wecksteen, C. / El Kaladi, A. (eds.), La traductologie dans tous ses états. Artois Presses Université: Arras 2007. 